\title{
Research on Characteristic Recognition and Dangerous Prevention While Mining through Collapse Column of Pansan Minefield,China
}

Haitao Xu

North China Institute of Science and Technology

hui yang ( $\sim 837784880 @ q q . c o m$ )

Shandong University of Science and Technology

Wenbin Sun

Shandong University of Science and Technology https://orcid.org/0000-0002-5008-7509

\section{Lingjun Kong}

Shandong University of Science and Technology

Peng Zhang

Shandong University of Science and Technology

\section{Research Article}

Keywords: collapse column, development characteristics, numerical simulation, failure depth, water inrush risk

Posted Date: August 26th, 2021

DOI: https://doi.org/10.21203/rs.3.rs-779433/v1

License: (c) (1) This work is licensed under a Creative Commons Attribution 4.0 International License. Read Full License 


\section{Abstract}

In order to find out the characteristics of geological isomer exposed in the mining process of 12318 working face in Pansan Mine and grasp its influence law on subsequent coal seams mining, the isomer was firstly determined as the collapse column by means of 3D seismic, transient electromagnetic detection, SYT detection and other methods, and its development characteristics, conductivity and water enrichment were identified.Then FLAC3D numerical simulation software was used to analyze the characteristics of vertical stress and plastic failure zone in different coal seams during mining.Finally, by comparing the ultimate failure depth of floor and the thickness of waterproof layer in the process of each coal seam directly pushing through the collapse column, the risk of water inrush and the prevention are analyzed.The results show that the exposed geological isomer is characterized by weak water-rich collapse column. Under the influence of the mining of the previous coal seam and the activation of the collapse column, the subsequent coal seam is in the low stress area before mining, which increases the floor failure and causes the activation of the collapse column more easily during mining.Coal $5 \#$ and $4 \#$ can be directly pushed through the collapse column, and coal pillar of sufficient width should be left for coal $1 \#$ to prevent the collapse column from activating water inrush.

\section{Introduction}

As the significant force of energy, coal resources are increasingly entering the stage of deep mining, the threat of water inrush caused by faults, collapse columns and other structures is becoming more and more serious,(Zhu et al.2011). In particular, the collapse column is a strong water-conducting channel. The amount of water inflow increases rapidly during the formation of the water inrush channel, which severely restricts the efficient and safe mining of coal ,(Yao et al.2012,Kong et al.2018).Reviewing the history of the collapse column research, domestic and foreign scholars have done a lot of theoretical analysis, numerical simulation and other research work. (Yin et al.2019) summarized the water inrush mode and mechanism, and derived the mechanical criteria for shear failure and thick-walled water inrush mode., revealed the delayed water inrush mechanism of the concealed subsidence column under the coal seam floor.(Yao et al.2018) established a multi-field coupling mechanical model of water-inrush of collapse column deformation, seepage and erosion, and numerically reproduced the whole process of water inrush development of coal mine floor under pressure collapse column.Changes in the mechanical parameters of the collapse column filling will increase the possibility of water inrush,(Lin et al.2021). When the plastic failure area of the coal seam floor and the plastic failure area of the karst collapse column are connected, the water inrush accident of the floor karst collapse column is prone to occur,(Cao et al.2021). The above research has greatly enriched the research results of the collapse column, but the research object is often a single coal seam.In fact, the mining of coal seams in Huainan is seriously threatened by collapse columns. In this paper, a variety of detection methods have found out the characteristics of the development of the exposed collapse column, and then the water inrush hazard of each coal seam is studied when multiple coal seams pass through the collapse column. 


\section{Characteristics Of Collapse Column \\ Working face condition}

Pansan Mine is located in the northwestern part of Huainan City, with well-developed structures in the minefield. The 12318 working face is the first mining working face of Pansan Minefield, located to the east of the downhill in the West No. 1 mining area, south of the F22 and F27 faults, north of the F1220 fault, and west of the $80 \mathrm{~m}$ waterproof coal pillar line. The strike length is from 1968 to $1974 \mathrm{~m}$, with an average of $1971 \mathrm{~m}$, and the slope length is $205 \mathrm{~m}$. The inclination angle of the coal seam on this surface is $6-47^{\circ}$, with an average of $14.5^{\circ}$, which is stable. The thickness of the coal seam is $1.1-5.6 \mathrm{~m}$, with an average of $3.3 \mathrm{~m}$. Adopt single-stroke longwall receding coal mining method, comprehensive mechanized coal mining technology, and all caving method to manage the roof.After the mining of $8 \#$ coal on this face exposed the collapse column, a $54 \mathrm{~m}$ waterproof coal column was set aside for skip mining. The stable water inrush at the back face was between $8-10 \mathrm{~m}^{3} / \mathrm{h}$ and the maximum water inrush speed was $125 \mathrm{~m}^{3} / \mathrm{h}$.After the test of water samples, the effluent water quality type of the working surface was $\mathrm{Cl}^{-}$$\mathrm{K}^{++} \mathrm{Na}^{+}$in the early stage, and $\mathrm{Cl}^{-}+\mathrm{HCO}_{3}{ }^{-}-\mathrm{K}^{++} \mathrm{Na}^{+}$in the later stage.In order to ensure the mining safety of the coal seams below $8 \#$ coal, the collapse column must be detected and studied.

When the karst cave develops to a certain scale, especially the deep lateral development, if the natural arch formed by the cave cannot withstand the gravity of the upper rock mass, the cave will collapse.The collapse columns exposed at the 12318 working face (Fig. 1b) are located in strips of ancient on the slope near the catchment area (or low-lying area).Affected by the direction of groundwater runoff during this period, the long axis direction of the collapse column formed by karst collapse is also close to the north-south direction, which is closely related to the topography of this period.

\section{Development characteristics}

In order to find out the morphological characteristics of the collapse column in the 12318 working face, downhole drilling and 3D seismic work were carried out. When the hole XIIXLZ3 was drilled to $591.86 \mathrm{~m}$, the hole leaked completely and the core was loose and broken. Combined with other related data, it was determined as the collapse column top interface, and the depth of the collapse column top boundary was $591.86 \mathrm{~m}$. Three-dimensional seismic exploration has become the preferred method of collapse column detection and is widely used,(Wu et al.2015).From the seismic time profile (Fig. 2), the spatial shape of the collapse column appears as a cone with a small upper part and a large lower part, with obvious zoning characteristics, and has the characteristics of a typical North China karst collapse column.

\section{Containment and conductivity}

\section{Large-depth transient electromagnetic detection}

The resistivity of rock mass and water is very different, and transient electromagnetic detection is widely used in the exploration of water-rich areas,(Chen et al.2015). The large-depth transient electromagnetic 
construction has completed 33 transient electromagnetic survey lines and 494 physical points (including 53 quality inspection points and 12 test points). The water richness and its distribution range of the 12318 subsidence column in the coal-measure strata in the first mining area of the west of the Pansan Mine in the survey area were ascertained.

The low-resistance area in the resistivity slice is a relatively water-rich area. In Fig. $\mathbf{4}$ above, there is no low-resistance phenomenon at the position of the northwestern collapse column, but a relatively highresistance state, which indicates that the collapse column is not rich in water. The location of the collapse column is not rich or weak, but there are two low-resistance anomalies around it. Low-resistance anomaly 1 and low-resistance anomaly 2 are delineated on the water-rich plan. The low-resistance anomaly is generally water-rich.

\section{SYT detection}

SYT detection uses natural geomagnetic waves to perceive the special physical characteristics of aquifers to determine water inrush channels and water richness, (Yang et al.2010). (Fig. 5a) shows the S6 section passing through the collapse column. From northwest to southeast, there are three vertical anomalous zones with low in-situ stress values. The north end of the geological anomaly body at 100 to 120 meters is the middle in-situ stress zone. (Fig. 5b) is the S7 section, passing through the collapse column. From the section, it can be seen that the in-situ stress value at the collapse column is medium and high, and the water richness is poor. (Fig. $5 \mathrm{c}$ ) shows the $\mathrm{S} 8$ section. There are two wide vertical waterrich zones from northwest to southeast, which are 300 meters and 500-600 meters, respectively, and the water richness is still poor at the collapse column.

Integrating the underground and drilling exposures and the above two geophysical exploration results, the conductivity, water richness and characteristics of the collapse column developed in the 12318 working face are as follows:the collapse column is generally weak or not rich in water in the coal-measure strata. The area affected by the collapse column and the nearby rock mass have a certain degree of water richness. Due to filling and compaction, the column body of the collapse column is less likely to be rich in water and water conduction. Due to the traction of the collapse column, the surrounding rock formations are stretched and damaged, and the fissures are relatively developed. The internal fissures are partially filled with water and show weak water richness. Ordovician ash and cold ash section are relatively developed in karst, and the water richness is relatively strong.

In the natural state, the collapse column has no conductivity in the coal-measure strata, and it is less likely to directly conduct the water from the deep Ordovician and cold ash aquifers to the coal seam. In order to analyze the impact of the collapse column on the mining of the $5 \#, 4 \#$ and $1 \#$ coal seams under mining conditions, FLAC is used to simulate the mining process to evaluate the safety of the fully mechanized mining face passing the collapse column.

\section{Build a collapse column model}


The simulated mining coal seams select the $5 \#$ coal, the $4 \#$ coal, and the $1 \#$ coal. The collapse column is located at the center of the model, and the top is at the top of the model. The lower ash layer may be closely hydraulically connected with the overlying Ordovician ash and cold ash water. According to the "Pansan Mine No. 2 Level Supplementary Exploration Geology Report", the water pressure of the ash is about 6.8MPa, which can be considered as a high-pressure aquifer.

The impact zone of the collapse column is dominated by fillings, and hydration reduces the strength of the fillings and also affects the evolution and expansion of the cracks in the water inrush channel,(Dong et al.2020,Yin et al.2021). The collapse column is simplified into a rectangular parallelepiped embedded in the model and the FLAC3D simulation calculation uses the Mohr-Coulomb material constitutive model. The established numerical model is shown in Fig. 6. The length (y direction), width (x direction) and height ( $z$ direction) are respectively $450 \mathrm{~m}, 340 \mathrm{~m}$, and $200 \mathrm{~m}$. The mining of the working face is carried out in the order from top to bottom.

The upper boundary condition of the numerical calculation is set as the self-weight stress of the overlying strata of the coal seam, and the lower floor is simplified as the displacement boundary condition, which can move in the $x$ and $y$ directions, and the $z$ direction is the fixed hinge support, ie $v=0$. The boundary conditions on both sides are solid coal and rock masses, simplified as displacement boundary conditions, which can move in the $z$ direction, and the other directions are fixed hinge bearings, that is, $u$ $=\mathrm{w}=0$.

Affected by both mining and structure, the depth of floor failure increases, (Liang et al.2020). The collapse column not only destroys the continuity of the coal seam, but also easily forms water inrush channels after activation ,(Sun et al.2015,Yao et al.2020).Through numerical simulation, the vertical stress distribution pattern around the collapse column and the plastic zone failure characteristic diagram during the coal seam advancement process are obtained. The stress change law and reason are analyzed, and the floor failure limit depth and the thickness of the water-resistant layer are compared. Knowing whether it can be directly pushed through the collapse column helps us make a water inrush risk assessment.

\section{Water inrush risk analysis The 5\# Coal Seam}

It can be seen from (Fig. 7a) the ZZ axis stress diagram that when the $5 \#$ coal seam is mined, the vertical stress of the floor $20 \mathrm{~m}$ drops from $19 \mathrm{MPa}$ to below $10 \mathrm{MPa}$, indicating that the excavation of the $5 \#$ coal seam mainly affects the rock mass within $20 \mathrm{~m}$ of the floor. It can be seen from (Fig. 7 b) that after the excavation of the 5th coal seam, since the 5th coal floor is made of fine sandstone with greater strength, its destruction depth is $11 \mathrm{~m}$ while the failure depth at the position of the collapse column is $30 \mathrm{~m}$,mainly shear failure. The distance between the $5 \#$ coal seam and the limestone aquifer is $138 \mathrm{~m}$, indicating that the $5 \#$ coal seam has the feasibility of pushing directly through the collapse column. 
In order to study the strain at different depths of the bottom plate, strain tracking curves are set at $5 \mathrm{~m}$, $15 \mathrm{~m}, 25 \mathrm{~m}$, and $35 \mathrm{~m}$ respectively at the bottom plate; it can be seen from (Fig. 7c) that when the working surface gradually advances to the boundary of the collapse column, the boundary of the collapse column is at $20 \mathrm{~m}$ away from the working face, the strain began to change significantly, indicating that when the sinking column was $40 \mathrm{~m}$ away from the working face, it began to have a slight impact, and when the sinking column was $20 \mathrm{~m}$ away from the working face,the impact is aggravated. When the working face is pushed past the sinking column, The bottom plate begins to bulge upwards, and the bulging amount of the bottom plate decreases as the depth increases.

\section{The 4\# Coal Seam}

It can be seen from (Fig. 8a) the ZZ axis stress diagram that due to the mining of coal seams $5 \#$ and $4 \#$, the stress in the floor rock mass is released. The rock mass within $100 \mathrm{~m}$ below the mining face floor of coal seam $4 \#$ is in the low pressure area, and the vertical stress is determined by previous mining, $19 \mathrm{MPa}$ has fallen below 10MPa. It can be seen from (Fig. 8b) that after the excavation of the 4\# coal seam, the 4\# coal floor rock mass is a relatively strong fine sandstone and the $4 \#$ coal seam is in a low pressure area due to the $5 \#$ coal seam mining, and the $4 \#$ coal seam floor damage depth is smaller,most tend to be less than $2 \mathrm{~m}$. The activation failure depth at the collapse column position can reach $35 \mathrm{~m}$, and the distance between the $4 \#$ coal seam and the limestone aquifer is $114 \mathrm{~m}$, indicating that the 4 th coal seam has the feasibility of pushing directly through the collapse column.

In order to study the strain at different depths of the bottom plate, strain tracking curves are set at $5 \mathrm{~m}$, $15 \mathrm{~m}, 25 \mathrm{~m}$, and $35 \mathrm{~m}$ of the bottom plate respectively. It can be seen from (Fig. $8 \mathrm{c}$ ) that when the working face gradually advances toward the boundary of the collapse column, the boundary of the collapse column is at $20 \mathrm{~m}$ away from the working face, the strain began to change significantly, indicating that when the sinking column was $40 \mathrm{~m}$ away from the working face, it began to have a slight impact, and when the sinking column was $20 \mathrm{~m}$ away from the working face, the impact increased.Among them, the strain rate of measuring point 1 is obviously higher than that of other measuring points, indicating that the rock mass within $15 \mathrm{~m}$ below the floor has been damaged.

\section{The 1\# coal seam comprehensive analysis Vertical stress analysis}

Observe the vertical stress diagrams of coal seam pushed to different positions. As shown in (Fig. 9), due to the mining of coal seams $5 \#$ and $4 \#$, coal seam $1 \#$ is in a low-stress area; during the mining process, the local stress in the collapse column and fracture zone changes.But on the whole, the collapse column and its edge fissure zone are still low-stress areas. When the coal seam is mined, within $60 \mathrm{~m}$ from the boundary of the collapse column, it begins to affect the collapse column; when the working face is pushed to $40 \mathrm{~m}$ away from the collapse column, a stress concentration area occurs in the coal pillar between the collapse column and the working face, indicating that this time The collapse column has affected the working face; when the working face is pushed to the boundary of the collapse column, the vertical concentrated stress disappears, and the surrounding rocks of the stope are all in the low-stress 
area, indicating that the stress of the surrounding rock has been released at this time, and the collapse column and its surroundings may have been activation.

\section{Plastic deformation analysis}

Observe the plastic map of surrounding rock at different locations in the observation 1 \# coal seam. As shown in (Fig. 10), when the working face is $60 \mathrm{~m}$ away from the boundary of the collapse column, local plastic failure occurs near the collapse column, but the scope is not large, and it is related to the aquifer and overlying rock. When the working face is $40 \mathrm{~m}$ away from the boundary of the collapse column, the damage range of the surrounding rock of the collapse column increases significantly, and plastic failure occurs under the bottom of the collapse column. When the working face is pushed to the boundary of the collapse column, the plastic failure in the collapse column is connected to the floor and the activated part of the collapse column during coal mining. As the working face continues to advance, the degree of activation of the collapse column becomes more serious.

\section{Feasibility Analysis of Passing Collapse Column}

It can be seen from (Fig. 11a) the ZZ axis stress diagram that due to the mining of the $5 \#$ and the $4 \#$ coal seams, the stress in the floor rock body is released, and the working face of the $1 \#$ coal seam is in the stress reduction zone, which is beneficial to the mining of the $1 \#$ coal seam. A certain range of increased stress is formed near the $4 \#$ mining face; the horizontal stress at the position of the collapse column has been released, indicating that due to the influence of coal seam mining, there has been activation within $30 \mathrm{~m}$ below the collapse column.

It can be seen from (Fig. 11b) that after the excavation of the 1\# coal seam, the rock strata in the collapse column has been completely destroyed, that is, the first collapse column is fully activated by the mining operation, and the collapse column can become a good water channel. The limestone aquifer is relatively close, about $23 \mathrm{~m}$, and the water pressure in the limestone aquifer is about $6.8 \mathrm{MPa}$, so it is not feasible to push the 1 \# coal seam directly through the collapse column.

It can be seen from (Fig. 11c) that when the sinking column is $60 \mathrm{~m}$ away from the working face, it starts to have a slight impact. When the sinking column is $20 \mathrm{~m}$ away from the working face, the impact increases. When the working face is pushed past the sinking column, the bottom plate begins to bulge upward. The amount of bulging decreases as the depth increases. Among them, the strain at the measuring point within $25 \mathrm{~m}$ below the mining face floor is significantly larger than other measuring points. It can be inferred that the rock mass within $25 \mathrm{~m}$ of the floor has been destroyed. The damage depth is already greater than the thickness of the water barrier by $17 \mathrm{~m}$. Therefore, it is not feasible for the 1 st coal to directly push through the collapse column, It is necessary to leave coal pillars of sufficient width.Measures such as advanced deep hole grouting reinforcement of the collapse column and strengthening of the activation monitoring of the collapse column should also be adopted.

\section{Conclusions}


(1) A variety of exploration methods under complex hydrogeology complement each other, and it is proved that the geological isomers disclosed are collapse columns with conductive and weak water-rich properties. The bottom plate at the location of the collapse column is affected by mining and the nature of the fillings, and the depth of damage is the largest after activation.

(2) Affected by the mining of the previous coal seam and the activation of the collapse column, the failure characteristics of the floor during the mining of the latter coal seam are enhanced and the collapse column is more likely to be activated.

(3) The maximum damage depth of the $5 \#$ and 4\#coal seam's floor is at the position of the collapse column and is much smaller than the thickness of the aquifer, indicating that the coal seam can be directly pushed through the collapse column. When the coal seam $1 \#$ is mined to the boundary of the collapse column, the collapse column and its surroundings are fully activated and connected, and the high-pressure water of the coal distance is less than the floor damage depth, and cannot be directly pushed through the coal column for mining. It is necessary to leave a sufficiently wide coal column and timely grouting prevention .

\section{Declarations}

Funding : This research was financially supported by the National Natural Science Foundation of China (51974172), Department of Education Shandong Province (2020KJH001).

Conflicts of interest: The authors declare that the research was conducted in the absence of any commercial or financial relationships that could be construed as a potential conflict of interest.

Data availability: All datasets generated for this study are included in the article/supplementary material.

Code availability $₫$ All materials are strictly regulated.

Authors' contributions $₫$ materials providing:HaitaoXu, data processing and thesis writing :Hui Yang,program design and writing guide :Wenbin Sun, language and image optimization :Lingjun Kong,Final summary and suggestions:Peng Zhang.

Ethics approval『Prepared carefully after preliminary work.

Consent to participate $\mathbb{A}$ All authors actively participate.

Consent for publication $₫$ All authors hope to publish successfully.

\section{References}

1. Zhu, W., Wei, C. (2011). Numerical simulation on mining-induced water inrushes related to geologic structures using a damage-based hydromechanical model. Environ Earth Sci 62, 43-54 .doi囚 


\subsection{7/s12665-010-0494-6}

2. Yao,B.(2012) Research on variable mass fluid-solid coupling dynamic theory of broken rockmass and application. Ph.D. Dissertation.China Univeristy of Mining and Technology, Xuzhou, China.(in

\section{Chinese)}

3. Kong, H., Wang, L. (2018)Seepage problems on fractured rock accompanying with mass loss during excavation in coal mines with karst collapse columns. Arab J Geosci 11,585 . doiه10.1007/s12517018-3881-z

4. Yin S.囚Lian H.囚Liu D囚et al. (2019). 70 years of investigation on Karst collapse column in North China Coalfield: cause of origin $₫$ mechanism and prevention. Coal Science and Technology47(11) : 1ه29凶 (in Chinese)

5. Yao,B., Chen,Z., Wei,J., Bai,T., Liu,S.(2018). Predicting Erosion-Induced Water Inrush of Karst Collapse Pillars Using Inverse Velocity Theory.Geofluids.doi:10.1155/2018/2090584

6. Lin,Z., Zhang,B., Gong,X.,Sun,L.,Wang,W.,Yang,D.et.al.(2021).Analysis and Application of the Mechanical Properties of the Karst Collapse Column Fillings.Shock and Vibration.doi:10.1155/2021/5519048

7. Cao,Z.,Ren,Y.,Wang,Q.,Yao,B.,Zhang,X.(2021).Evolution Mechanism of Water-Conducting Channel of Collapse Column in Karst Mining Area of Southwest China.Geofluids ,doi:10.1155/2021/6630462

8. Wu, B., Kong, J. Dong, S. (2020). Seismic attribute method for concealed collapse column identification in coal fields. Acta Geod Geophys 55, 11-21 . doi:10.1007/s40328-019-00278-0

9. Chen, W., Xue, G, Muhammad, et.al.(2015) Application of Short-Offset TEM (SOTEM) Technique in Mapping Water-Enriched Zones of Coal Stratum, an Example from East China.Pure Appl.

Geophys.172,1643-1651 .doi:10.1007/s00024-014-1028-z

10. Yang W., Song G. Lian H.(2010). The study of application on geological conditions of mine water inrush by SYT electrom agnetic wave method exploration.Journal of North China Institute of Science and Technology, $7(1): 16-18$.(in Chinese)

11. Dong,F., Zhang, P., Sun, W., Zhou, S., Kong, L. (2021). Experimental research on the effect of waterrock interaction in filling media of fault structure. Geomechanics and Engineering, 24(5), 471-478. doi:10.12989/GAE.2021.24.5.471

12. Yin,L., Li,M., Sun W., Chen,J.,Liu,B.,Wang,Z. (2021). Mechanical Mechanism and Propagation Law of Fissure-Tip Cracks of Large-Size Rock Specimens with Two Precut Fissures.Shock and Vibration.doi:10.1155/2021/8812902

13. Liang,Z. , Song,W ., Liu,W., (2020). Theoretical models for simulating the failure range and stability of inclined floor strata induced by mining and hydraulic pressure.Int. J. Rock Mech. Min. Sci.doi.:10.1016/j.jirmms.2020.104382

14. Sun, W., Xue, Y., Li, T. et al. (2019). Multi-field Coupling of Water Inrush Channel Formation in a Deep Mine with a Buried Fault. Mine Water Environ 38, 528-535 . doi:10.1007/s10230-019-00616-2

15. Yao,Q., Zheng,C., Tang,C., Xu,Q., Chong,Z., Li,X. (2020). Experimental Investigation of the Mechanical Failure Behavior of Coal Specimens With Water Intrusion.Front. Earth 


\section{Figures}

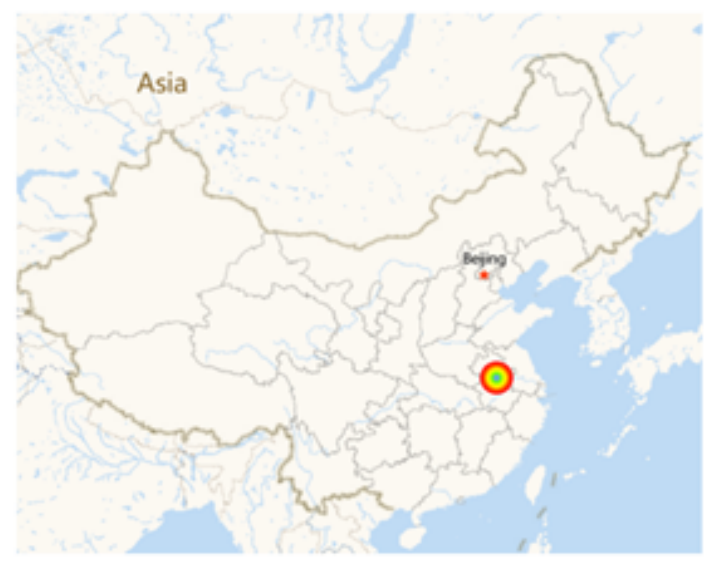

(a)

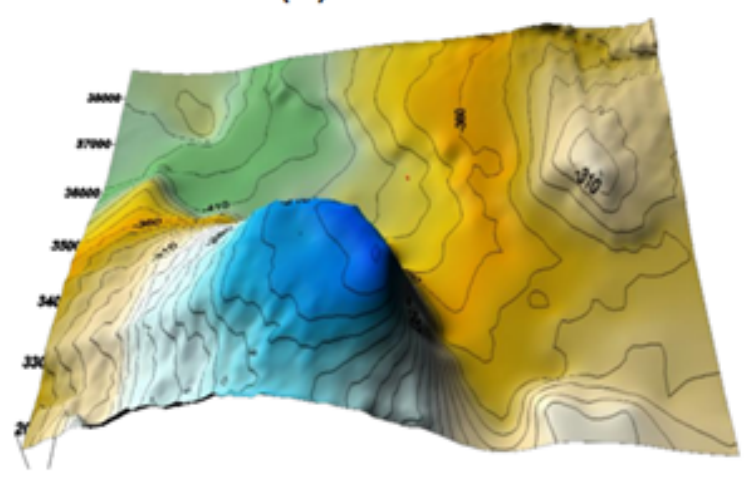

(b)

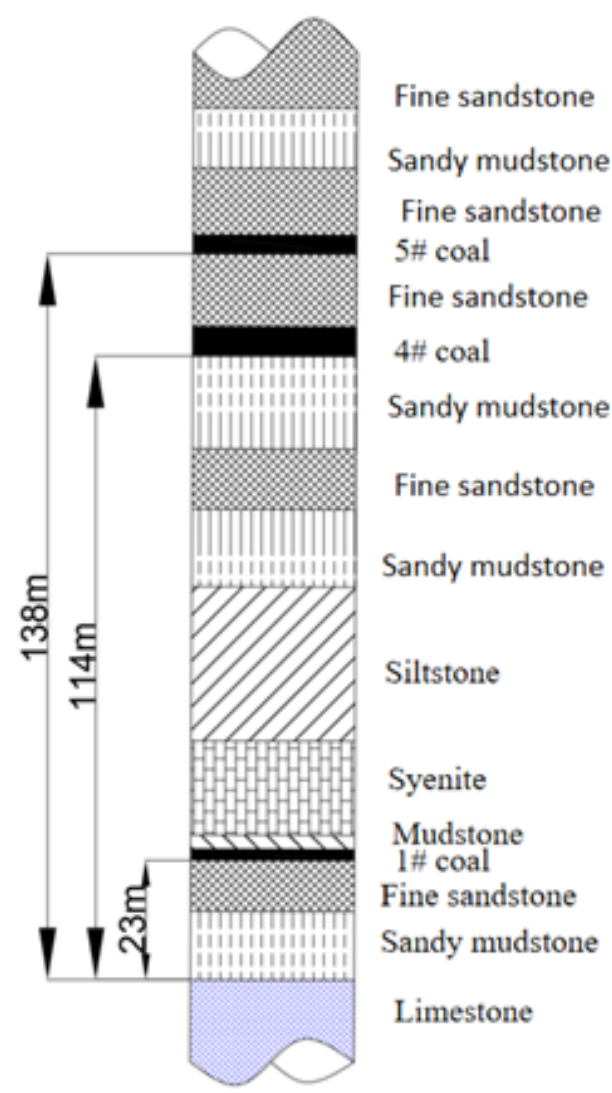

(c)

\section{Figure 1}

Engineering Background:(a)Collapse column location map,(b)Three-dimensional map of early geomorphology,(c)Histogram of main rock formations 


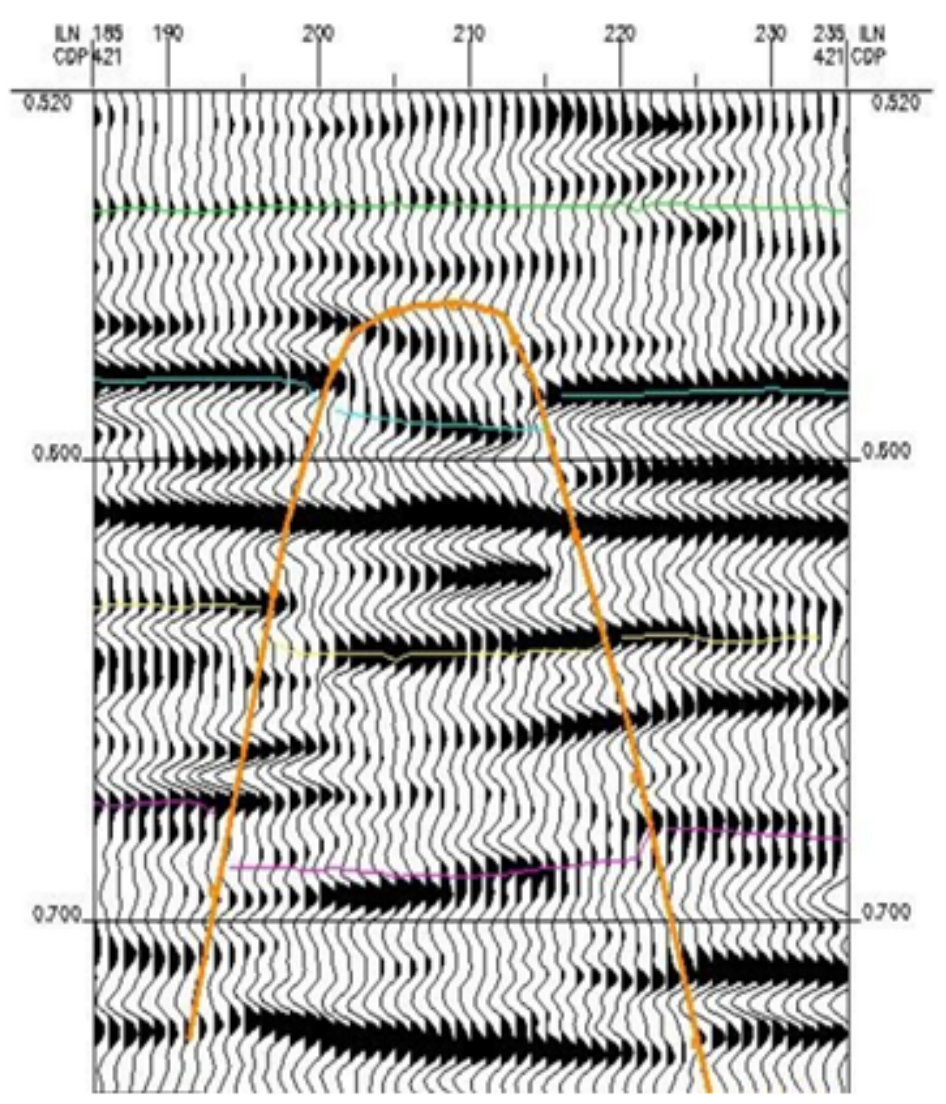

Figure 2

The reflection of the collapse column on the seismic time profile

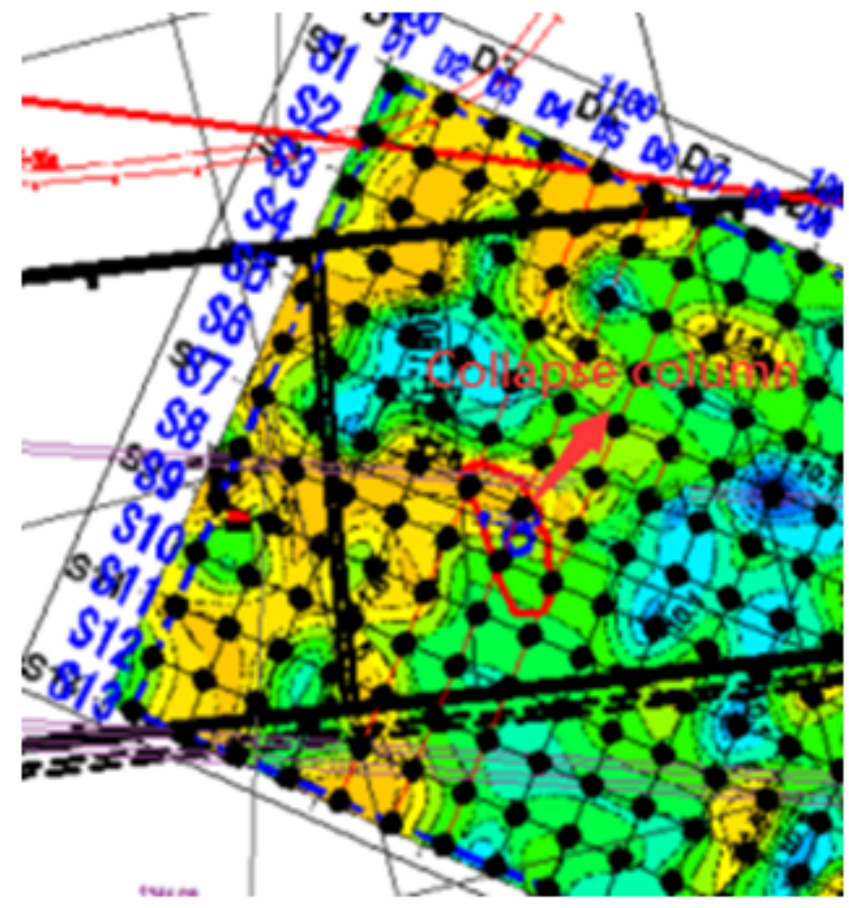


Figure 3

Schematic diagram of overlaying transient electromagnetic exploration area

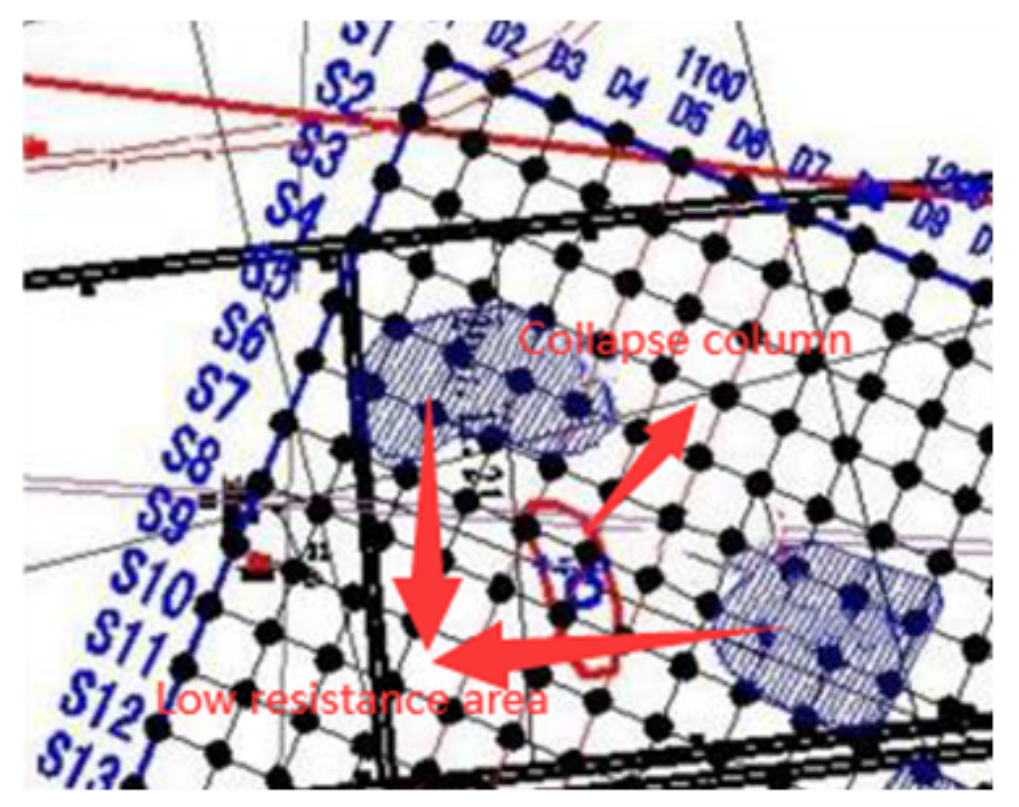

Figure 4

Distribution of abnormal areas

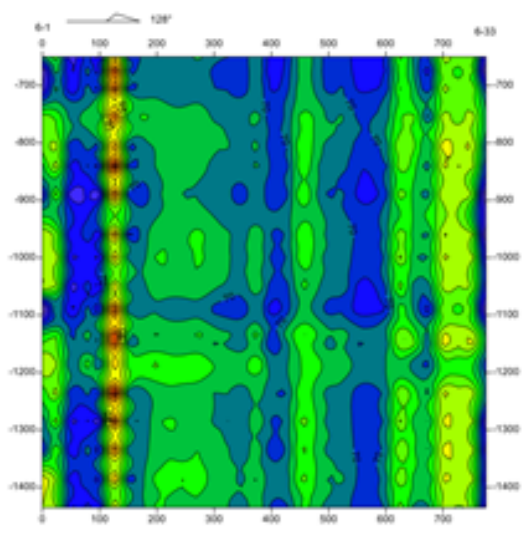

(a)

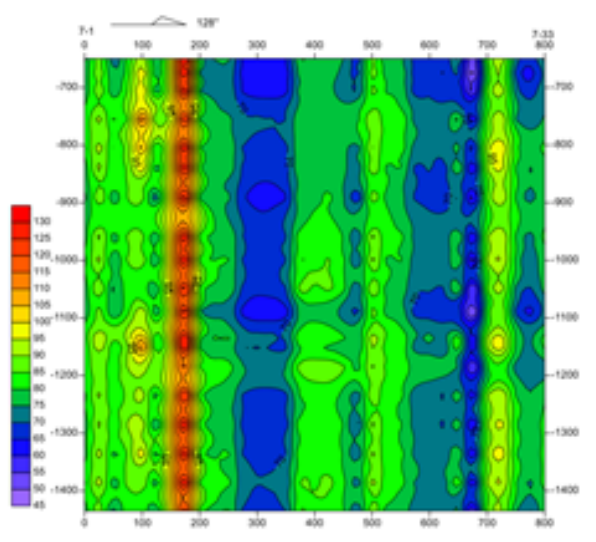

(b)

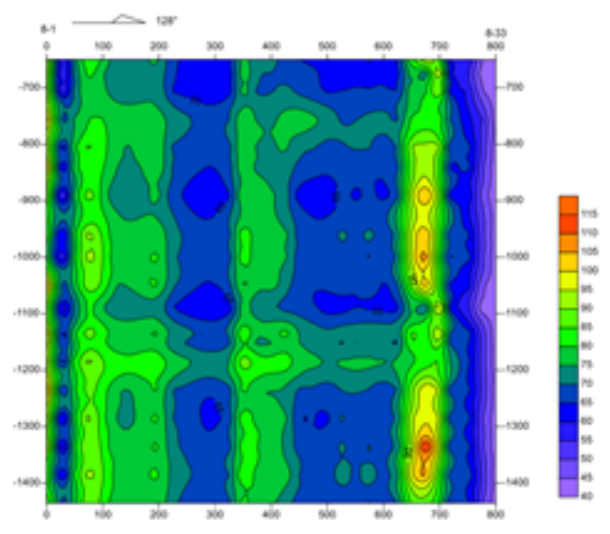

(c)

Figure 5

Pseudo-section view of ground stress on line (a)S6,(b)S7,(c)S8 


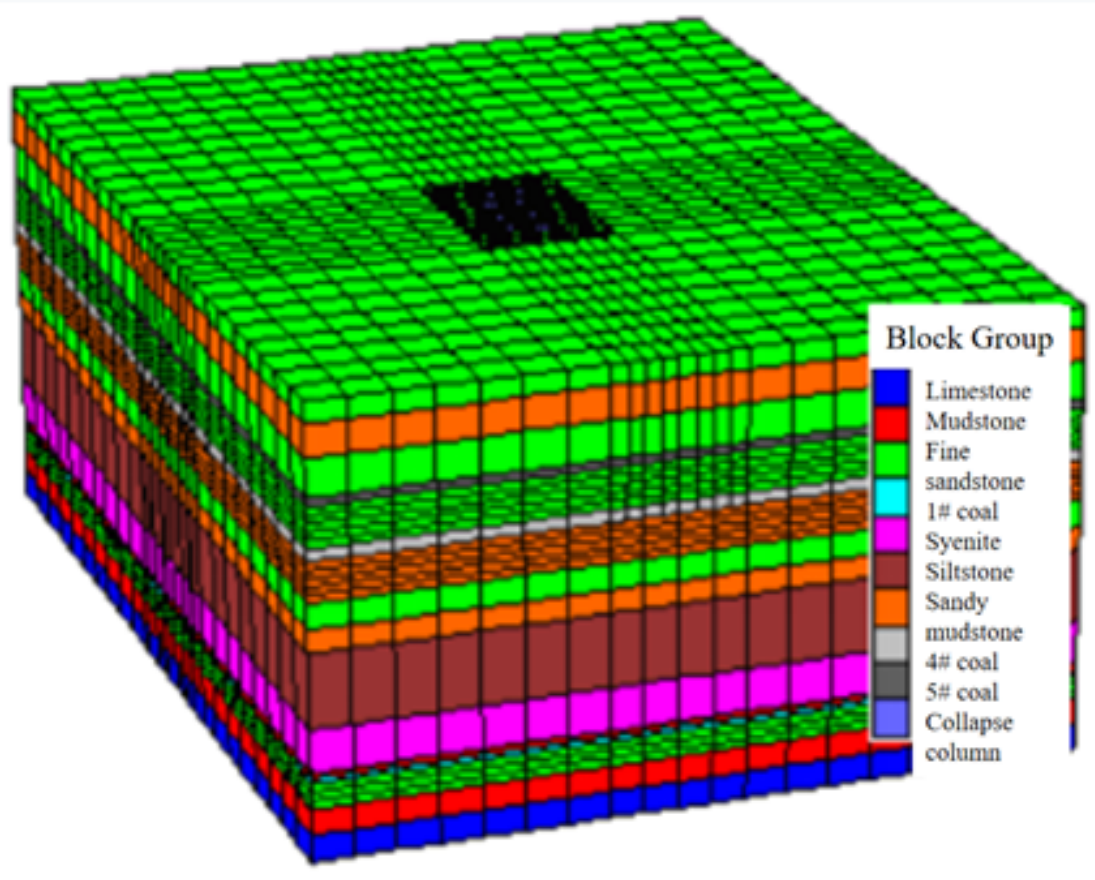

Figure 6

Three-dimensional calculation mode diagram

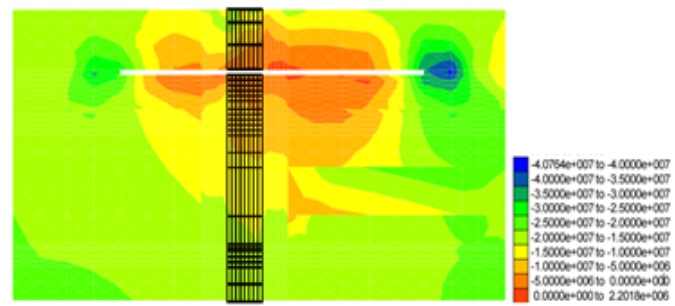

(a)

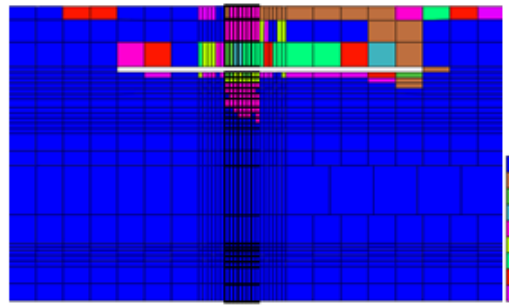

(b)

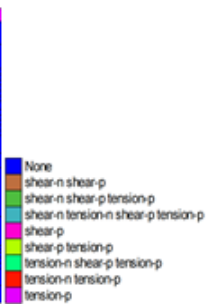

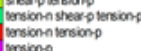

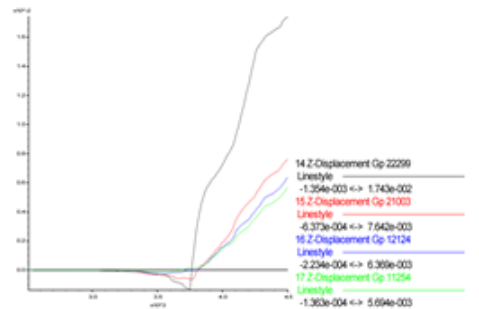

(c)

\section{Figure 7}

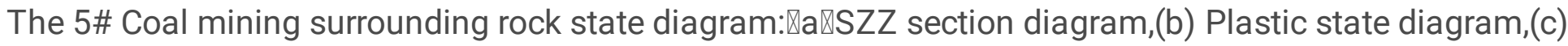
Bottom plate strain diagram

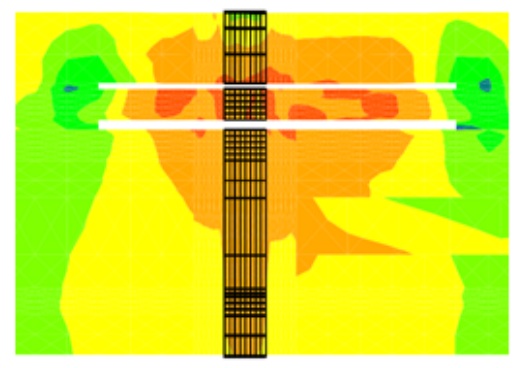

(a)

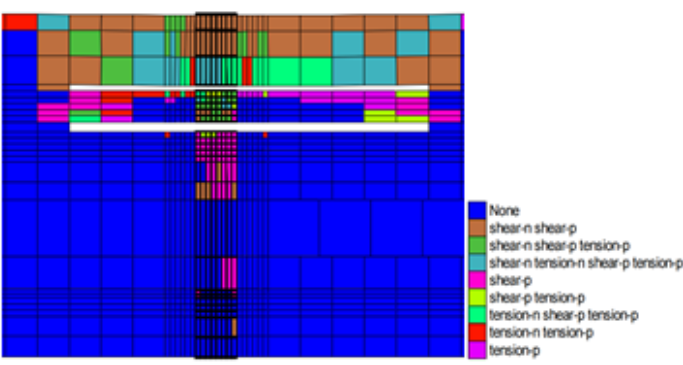

(b)

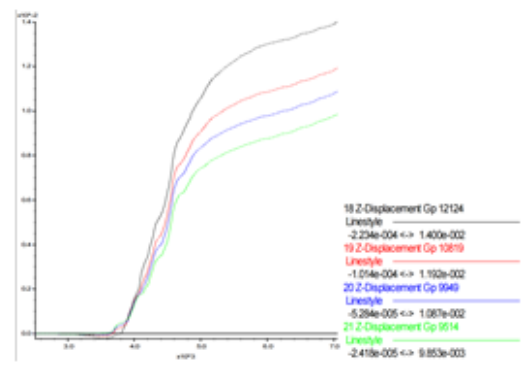

(c)

Figure 8 
The 4\# Coal mining surrounding rock state diagram: (a) SZZ section diagram,(b) Plastic state diagram, (c) Bottom plate strain diagram

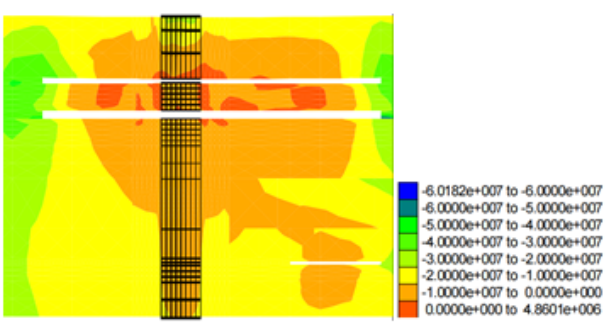

(a)

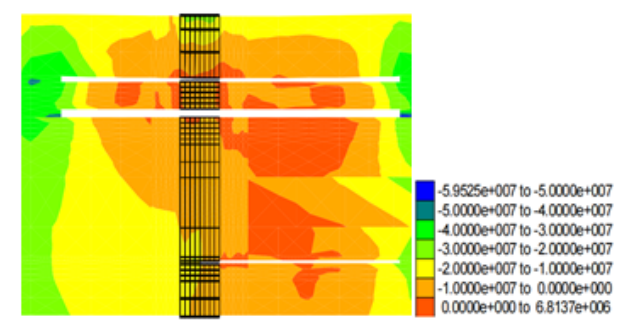

(d)

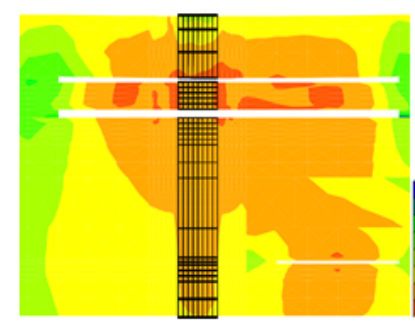

(b)

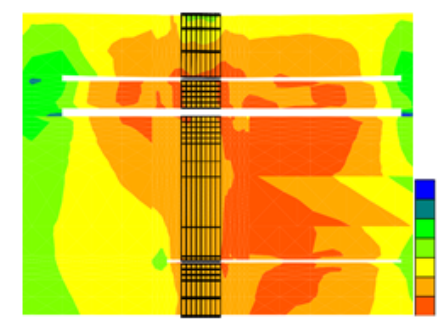

(e)

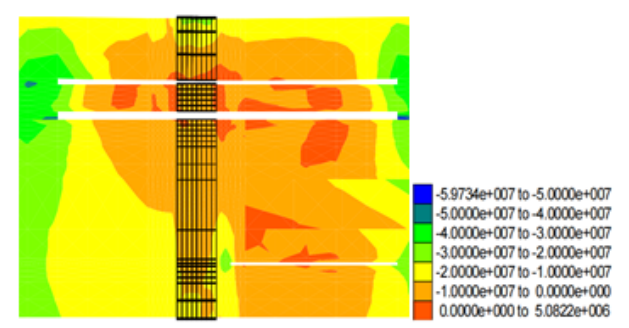

(c)

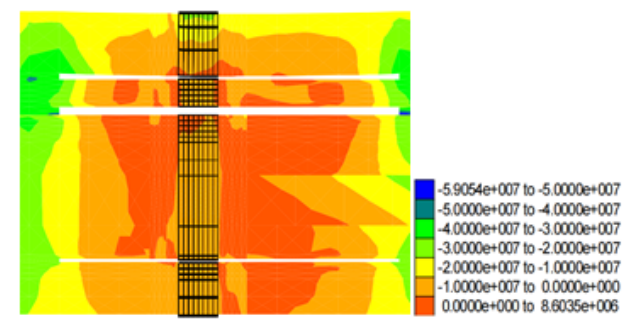

(f)

\section{Figure 9}

Vertical stress diagram of the 1 \# coal seam pushed to different positions:(a) $60 \mathrm{~m}$, (b) $40 \mathrm{~m}$,(c) $20 \mathrm{mto}$ the boundary (d) push to(e)push out (f) $80 \mathrm{~m}$ past the boundary

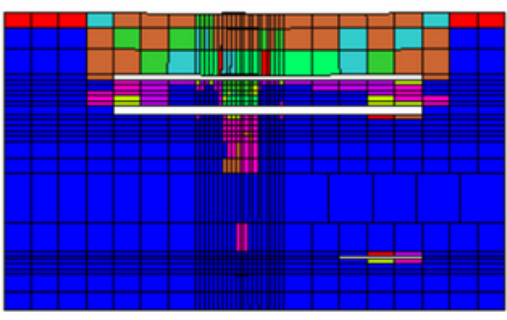

(a)

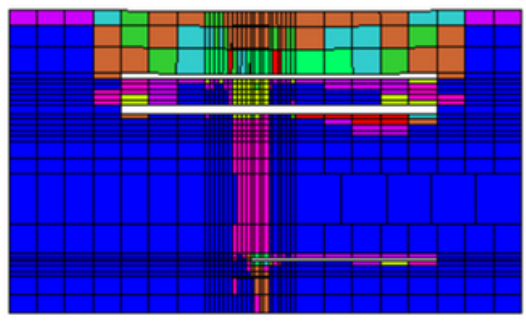

(d)

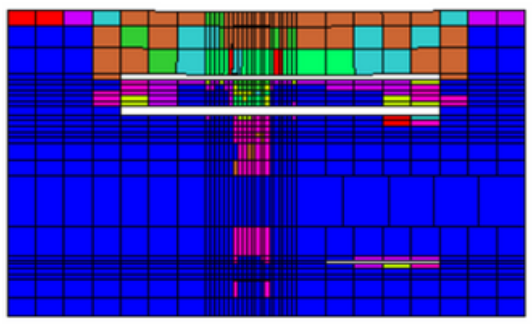

(b)

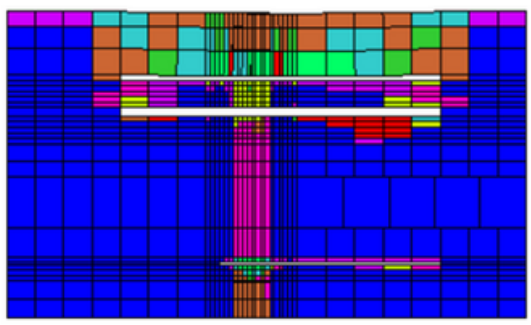

(e)

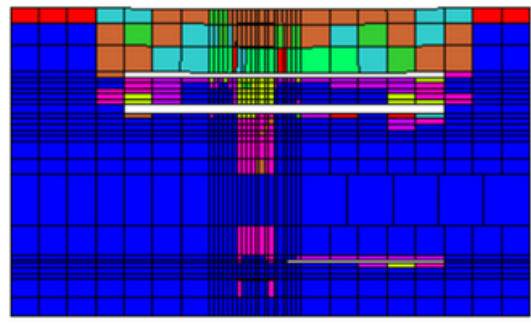

(c)

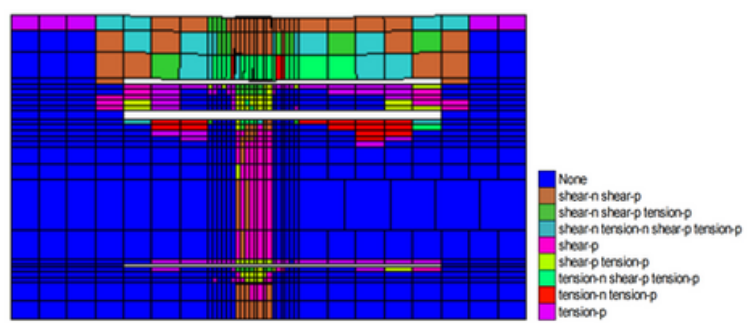

(f)

Figure 10 
Plasticity map of surrounding rock at different locations of the 1 \# coal seam:(a) $60 \mathrm{~m}$,(b) $40 \mathrm{~m}$,(c) $20 \mathrm{~m}$ to the boundary (d) push to(e)push out (f) $80 \mathrm{~m}$ past the boundary

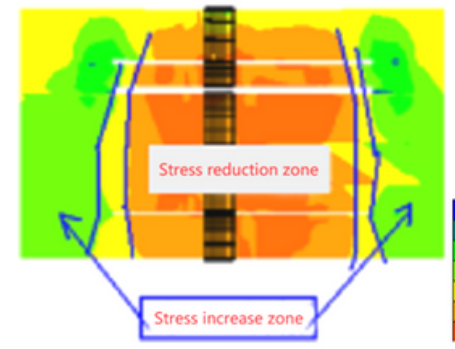

(a)

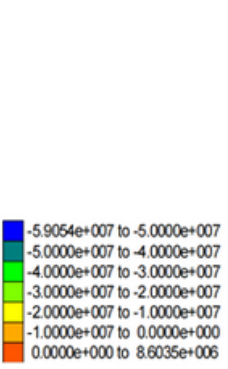

$0.0000 \mathrm{e}+0000$ to $8.6035 \mathrm{e}+006$

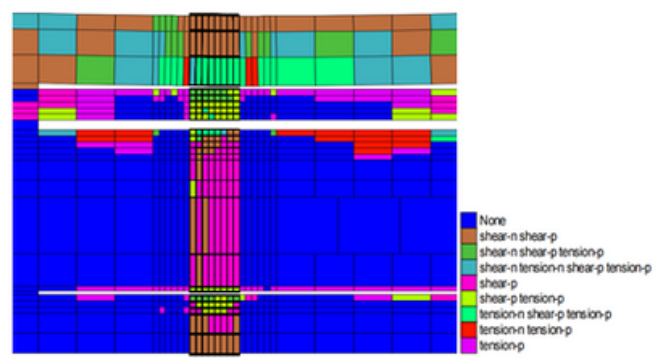

(b)

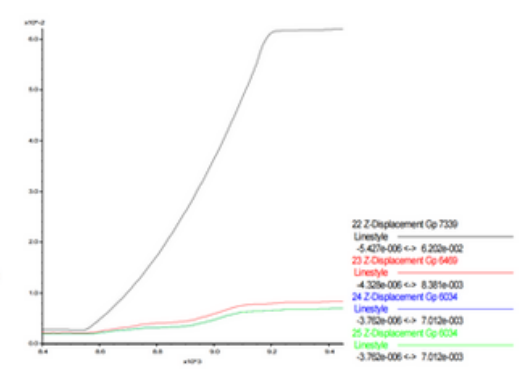

(c)

\section{Figure 11}

The 1\# Coal mining surrounding rock state diagram:(a) SZZ section diagram,(b) Plastic state diagram,(c) Bottom plate strain diagram. 